This is the author version of the paper accepted for publication by

the International Journal of Inclusive Education.

The published version can be found

at https://doi.org/10.1080/13603116.2019.1620880

\title{
Constraints to the implementation of inclusive teaching: A Cultural Historical Activity Theory approach
}

\author{
Douglas Andrews ${ }^{\mathrm{a} *}$, Elizabeth Walton ${ }^{\mathrm{ab}}$ and Ruksana Osman ${ }^{\mathrm{a}}$ \\ ${ }^{a}$ School of Education, University of the Witwatersrand, Johannesburg, South Africa \\ ${ }^{b}$ School of Education, University of Nottingham, Nottingham, UK \\ * Douglas Andrews, predterm@gmail.com, Wits School of Education, Private Bag 3, \\ Wits 2050, South Africa
}

\begin{abstract}
Learners who experience learning challenges are at risk of not accessing equitable education opportunities in South African schools. This is despite teacher education and system reform initiatives towards more inclusive education. To discover what constrains inclusive teaching, we conducted a qualitative study at four schools in a South African city. At each research site teachers and principals were interviewed and we found teacher, school and system factors implicated in the non-implementation of inclusive teaching practices. In discussing these factors through a Cultural Historical Activity Theory lens, we identify four objects of school activity which are not aligned to inclusive education. These are a competitive ethos, rigid curriculum compliance, bell-curve thinking, and survival in the face of resource limitations. We argue that inclusive teaching will be constrained where it is not aligned with schools' objects-of-activity. To conclude, we suggest strategies that might help to transform objects-of-activity to promote equity and inclusion.
\end{abstract}

Keywords: Inclusive teaching, Cultural Historical Activity Theory, object-ofactivity, activity systems 


\section{Introduction}

There is increasing international impetus for the realisation of inclusive education, with the theme for the Global Education Monitoring Report (GEMR) 2020 being 'inclusion'. The Concept Note for the GEMR 2020 (UNESCO 2018) describes the different elements needed for inclusive education as government and finance; laws and policy; curriculum and learning materials; personnel (teachers, school leaders and support staff); schools; and communities, parents and students. The Concept Note also asks various questions, one of which is 'How can common obstacles to the implementation of ... inclusive education policies be anticipated and overcome?' (UNESCO 2018,8). We are interested in understanding why there seems to be slow progress towards inclusive education, even when these obstacles are reduced. Our focus is South Africa, a middle-income country which has committed itself to developing inclusive education.

The guiding principles of The Salamanca Statement and Framework for Action (UNESCO 1994) were adopted by South Africa to address policies and practices that discriminated against children with disabilities. Education White Paper Six: Special Needs Education (WP6) (Department of Education (DoE) (2001) provides a framework for the implementation of inclusive teaching in South African schools. Even with this policy, many learners do not receive the support that they require to succeed at school (Ladbrook 2009; Geldenhuys and Wevers 2013). Despite ongoing research into the factors that constrain inclusive education in South African schools, little is known about what affects teachers' ability to teach inclusively. This article reports on a section of a qualitative study, conducted with teachers and principals from four different schools in a South African city. First, we situate our work within a broader context of research in inclusive teaching in South African schools. We then describe the theoretical framework (Cultural Historical Activity Theory [CHAT]) and the associated concept of 
the object-of-activity, the research process and outline the findings. Analyses of the findings suggest that when the hidden, internal motives that inform the object-ofactivity in a school are not aligned with the aims and ideals of inclusive education, inclusive teaching is constrained.

\section{Inclusive Education}

Inclusive education has global reach and is supported by international policy, including Article 24 of the United Nations (UN) Convention on the Rights of Persons with Disability (CRPD) (UN 2006) and the Fourth Sustainable Development Goal (UN 2015). The 2016 comment on the CRPD states that,

\footnotetext{
The right to inclusive education encompasses a transformation in culture, policy and practice in all formal and informal educational environments to accommodate the differing requirements and identities of individual students, together with a commitment to remove the barriers that impede that possibility. (UN 2016,3)
}

The histories and geographies of exclusion in different contexts account for the different challenges of inclusive education, and as a result, it can be expected to be implemented differently in different countries. South Africa has particular challenges, given its legacy of inequitable educational provision.

\section{The South African context}

Inclusive education in South Africa is aligned with the country's constitution, which speaks of the achievement of equality and the advancement of human rights and freedoms. According to WP6 (DoE 2001), inclusive education is about acknowledging that all learners can learn and are entitled to quality and equitable support. It means minimising barriers to learning and maximising the participation of every child in a school's culture and curriculum. WP6 distances itself from ideas and practices of 
special education, which are founded on a medical-deficit approach to learner difference. WP6 asserts that it is the responsibility of the school and the education system to meet the needs of all learners through appropriate teaching strategies and learner support. Inclusive schools value collaborative teaching and learning and are committed to success and achievement for all (Engelbrecht 2004). One of the ways inclusive education may be realised is by using inclusive teaching practices.

\section{Inclusive teaching}

The ideals of inclusive education must be translated into the realities of classroom practice through inclusive teaching. Scholars have offered descriptions and conceptual frameworks on what inclusive teaching means (Ainscow and Cesar 2006; Nilholm and Alm 2010). We see inclusive teaching operating at the confluence of the elements of inclusive education mentioned by the GEMR 2020 Concept Note (Unesco 2018). These include personnel (teachers and school leaders), schools (culture and resources), school curricula, and community (learners).

Teachers are key role players in the realisation of inclusive education (DoE 2001) and must enact inclusive teaching. Inclusive teachers can be expected to value learner diversity, to support all learners, work collaboratively with others, and to engage in ongoing professional development (EADSNE 2012). Their effectiveness depends on teacher education, positive attitudes and dispositions, pedagogical skill, understanding of diverse learning needs and self-efficacy (Nel, Tlale, Engelbrecht and Nel 2016). School leadership is a determinant of the extent to which inclusive education gains traction in a school and whether teachers are supported through school structures and resources to teach inclusively (Walton 2011; Gous, Eloff and Moen 2014). Inclusive teaching takes place in schools, where an inclusive school culture is crucial (Booth et al. 
2002) and where resources are harnessed to secure access, participation and success for all.

Inclusive teaching respects, values and understands learner diversity as a resource that 'enhances learning opportunities' (EADSNE 2012,12). Inclusive teachers are concerned with the achievement of all learners (Florian and Black-Hawkins (2011). This requires a disruption to bell-curve thinking which attempts merely to do the 'greatest good for the greatest number'. Bell curve thinking 'implies that what is ordinarily available will meet the needs of most learners while some at the tail ends of a normal distribution may require something additional or different' (Florian 2015,7). The result of bell-curve thinking is that those falling outside of the mean distribution are ascribed a deficit label which sets them apart from others and ultimately marginalises them. Inclusive teaching demands curricula that are learner-centred, flexible and accessible to learners with different backgrounds and learning needs. Such curricula need to support diverse instructional strategies and modes of assessment (Unesco 2018; DoE 2001).

\section{Accounting for the non-implementation of inclusive teaching in South Africa}

Even though inclusive teaching is founded on human rights and espouses values of nondiscrimination, equity and dignity, its implementation in South Africa has been limited and difficult to achieve (Engelbrecht and Van Deventer 2013; Schafer and Wilmot 2012). Research (Engelbrecht et al. 2016) indicates that a gap exists between the ideals of policy stipulation and the reality of implementation, where many schools do not consider the diverse learning needs of learners, despite efforts by individual teachers.

Various scholars have identified the factors which account for the nonimplementation of inclusive teaching in South Africa. The uptake of inclusive teaching 
is said to be limited by a stringent curriculum that focuses on subject content, inflexible time frames, reliance on external assessment and prescriptive design (Geldenhuys et al. 2016). A second factor is a lack of resources in schools and socioeconomic challenges (Soudien and Sayed 2004; Wildeman and Nomdo 2007). Thirdly, negative teacher attitudes, low teacher self-efficacy and negative parent attitudes are said to inhibit inclusive teaching (Ekins, Savolainen and Engelbrecht 2016; Engelbrecht et al. 2005). Teacher education has also been found to be inadequate, with some programmes being criticised for being disjointed, too theoretically orientated, fragmented, and focusing on a deficit-orientated approach to learning difficulties (Engelbrecht 2013). Furthermore, conflict between the ideas of inclusive teaching and the ideas of special-needs teaching methods create confusion and impact negatively on the implementation of inclusive teaching (Van Rooyen, Le Grange and Newmark 2002). Scholars (Engelbrecht and Van Deventer 2013; Engelbrecht et al. 2016) explain that WP6, despite a stated position on the socially-constructed nature of learner difference, still relies on a medical approach for the support of learners with diverse barriers. WP6 advocates for a continuum of support for learners where those with minimum or low-intensive needs receive support in mainstream schools, those with moderate needs in full-service schools and those requiring high need support be accommodated in special schools. This has led to South Africa's inclusive education policy being characterised by both conflict of ideas and ambiguity (Donohue and Bornman 2014).

A logical assumption is that by addressing these constraints schools can become more inclusive. However, it becomes difficult to account for those schools where human and physical resources are abundant and inclusive teaching continues to be constrained. Similarly, many newly qualified and in-service teachers still do not teach inclusively despite having attended courses on inclusive teaching (Walton et al. 2014). 
This suggests the need to consider factors that are hidden, or remain below the surface, to account for the lack of inclusive teaching in schools. We argue that researching the complexity of schools from a CHAT perspective (Engestrom 2001) will allow for the identification of factors that do not become visible when considering components in a school in isolation from the rest of the school system. We then assert that a significant constraint to inclusive teaching is when the historically motivated object-of-activity (Kaptelinin 2005) in a school is misaligned with the ideas of inclusive teaching.

\section{The object of activity as a theoretical concept in Cultural Historical Activity Theory}

The object-of-activity is difficult to define and essentially transforms and evolves as a result of the emergence of contradictions between subjects and objects in a cultural system (Kaptelinin 2005; Stetsenko 2005). Scholars (Engestrom 1999; Foot 2002) argue that the object is shaped and directed by activity and that understanding the activity in a system hinges on understanding the object. The object-of-activity can be referred to as the 'sense-maker' that gives meaning to and determines the values of various phenomena. It is a dynamic entity that is constructed and transformed by the various constraints that exist in systems. These constraints include 'The needs that the activity at hand is striving to satisfy, available means, other potentially related activities, and other actors involved, each with their own motives and objects' (Kaptelinin 2005,17).

To understand the object-of-activity the historical 'motives' and the 'needs' that informed the original creation of the object and the activity system need to be investigated (Kaptelinin 2005). Then, to understand the concept of the 'motive', CHAT's third basic principle of historicity needs to be considered. No activity taking place within an activity system can be properly understood without examining the 
hidden sediments and evolutions of the object over time (Engestrom 1993; Ellis 2011; Foot 2002). From a social perspective, objects in an activity system are constructed with the help, and under the influence, of historically accumulated collective experience (Engestrom 1999).

In this study, the activity systems are the schools. The subject component are the teachers whose actions and collective activity we wish to understand (Beatty and Feldman 2012). The division-of-labour component is the way that all the important roles and responsibilities throughout the system are covered and is described as the explicit and implicit organisation within the school community and the vertical divisions between power and status. School principals dominate this component of the system. The artefacts are the physical and intellectual tools available as a resource to assist with teaching, while the community component refers to the collection of all actors in a system, engaged in collective activity with the subject, who all share an interest in the object-of-activity. Finally, the operational directives of the school are the rules component. The rules component constitutes the explicit and implicit regulations, norms, conventions and social relations that shape the community members (Beatty and Feldman 2012). Figure 1 below shows these interactive relationships between the components of a school within Engestrom's (2000) activity systems model. Wells $(1996,76)$ explains how the top portion of Engestrom's model represents the subjectobject relationship and 'is related to the larger cultural and historical context by the relationships represented by the other triangles.' 


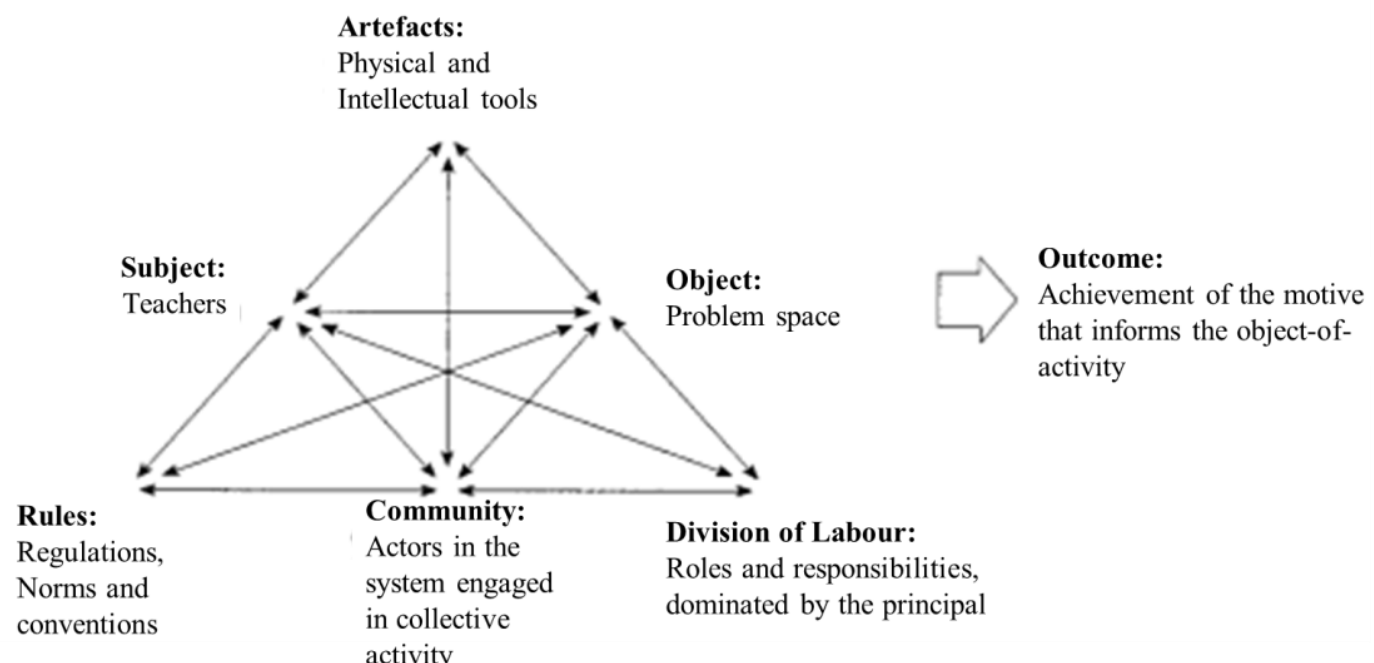

\section{Figure 1: Components of a school system}

\section{Research design and methodology}

This study followed a qualitative research design. This was an interpretive study, as we wanted to understand the meaning the participants attributed to their subjective experiences and the world (Merriam 2002; Willig 2008). Purposive sampling was used to select four primary schools in a South African city (not named to protect identity) (Teddlie and Yu 2007). These schools represent a variety of schools - affluent independent; faith-based, pro-poor independent; and state-run schools available in the city. Data were collected at the schools in 2015 and 2016. This article reports on constraints to inclusive teaching, but it is derived from a wider study that also considered enablers of inclusive teaching.

\section{Participants}

The participants were the principals and two or three intermediate phase teachers in each school. Because this project was part of a larger funded project into teacher 
education for inclusive education in South Africa, we purposively selected teachers educated at South African universities. The teacher sample represents both male and female teachers and a range of diverse cultures and ethnicities. Table 1 below shows the role of the research participants in the schools, their gender, the grade the teachers taught and their teaching experience. The teachers' names are pseudonyms to protect the anonymity of the participants.

\begin{tabular}{|c|c|c|c|}
\hline POSITION & GENDER & GRADE & YEARS OF TEACHING EXPERIENCE \\
\hline \multicolumn{4}{|l|}{ SCHOOL A } \\
\hline Principal & Male & $\mathrm{n} / \mathrm{a}$ & 35 \\
\hline Georgina & Female & 5 & 4 \\
\hline Teresa & Female & 6 & 9 \\
\hline \multicolumn{4}{|l|}{ SCHOOL B } \\
\hline Principal & Male & $\mathrm{n} / \mathrm{a}$ & 30 \\
\hline Sarah & Female & 5 & 7 \\
\hline Helen & Female & 5 & 7 \\
\hline \multicolumn{4}{|l|}{ SCHOOL C } \\
\hline Principal & Male & $\mathrm{n} / \mathrm{a}$ & 42 \\
\hline Vicky & Female & 6 & 7 \\
\hline Charlene & Female & 6 & 8 \\
\hline \multicolumn{4}{|l|}{ SCHOOL D } \\
\hline Principal & Male & $\mathrm{n} / \mathrm{a}$ & 33 \\
\hline Lydia & Female & 6 & 8 \\
\hline Olive & Female & 5 & 8 \\
\hline Philemon & Male & 6 & 9 \\
\hline
\end{tabular}




\section{Table 1. Information about the teachers and principals}

\section{Data collection}

The reported findings are based on data collected through individual, semi-structured interviews (McMillan and Schumacher 2010) with the principals and the teachers. This allowed us to explore opinions and perceptions of complex and sensitive issues. We first interviewed the schools' principals to understand the school environment and its stance on inclusive teaching. Teachers were asked questions concerning what they thought enabled or constrained them from including all learners in teaching and learning activities. We made it clear that participation was voluntary and there would be no negative consequences for refusal to participate. We put measures in place to minimise foreseeable risks (emotional distress, informational risk or embarrassment) that could result from a breach in confidentiality, these included pre-negotiation of the structure of the contact-time, using pseudonyms, conducting interviews in private and obtaining written consent prior to participation (Singh and Wassenaar 2016). Ethics clearance was obtained for this study and permission to conduct the research in the schools was granted by the relevant provincial department of education.

\section{Data analysis}

The purpose of the analysis was to organise, account for, and give an explanation of the data in relation to the participants' definition of their situation (Cohen, Manion and Morrison 2002). The interview transcriptions were analysed thematically (McMillan and Schumacher 2010), guided by 'sensitising concepts' (Bryman 2012,388) derived from the research question. First, segments of data were named as codes which were then used as indexing devices to identify similar segments or chunks from the transcriptions (MacQueen et al. 1998). These codes, with the similar segments of data, 
were then grouped into categories, which were collapsed into the main themes. The themes emerging from this inductive data analysis process were then considered within the framework of Engestrom's (2000) activity systems models. The purpose of this was to make sense of the actions of the participants in terms of the wider system of the collective activity of their school. Using activity systems allowed us to utilise Roth and Tobin's (2002) idea of 'zooming in' on interactions between components and certain components themselves while not ignoring the impact of other elements or components within the system.

\section{Credibility and trustworthiness, and limitations of the study}

We employed strategies to ensure that results from our data were credible, fair, authentic and trustworthy. These included firstly, the prolonged engagement in the field to build trust and rapport with our participants. This was deemed to be necessary as the more perspectives we gathered from our interviews the better we understood the context of the participant views. Second, describing the settings and the participants and conducting interim data analyses to refine our ideas ensured that there were matches between evidence-based categories and the reality of the participants (McMillan and Schumacher 2010; Creswell and Miller 2000). The generalisability of the study is limited by the scope of the study, with a relatively small number of schools and participants.

\section{School Biographies}

The four schools differ from each other with regard to the availability of resources and community influence. They are similar in that they follow the South African Curriculum and Assessment Policy (CAPS), they are co-educational and have a learner population of between 700 and 800 learners, and all four schools are primary schools. 
School A is a well-resourced, fee-paying, independent institution located in a wealthy community. It provides a learning-support centre with permanently employed specialists. It promotes academic competition between learners and is assessment and performance driven. Compulsory, additional enrichment subjects are included in the timetable with the intention that learners in this school have a competitive advantage.

School B is an independent school where most learners come from economically deprived communities. Most families cannot afford to pay school fees and the shortfall is taken up by subsidies from the religious organisation to which it is affiliated. The school is challenged with staffing shortages and cannot remunerate a full staff quota. Although historically a religious school, religious affiliation is not a precondition for registration.

School C is a suburban, public school that charges fees, but does receive a state subsidy to accommodate a large non-fee-paying cohort of learners. Due to the urban density of its location it is oversubscribed in relation to its infrastructure. The school enjoys many of the privileges of its location in a middle-class neighbourhood and it has an active school governing body that advocates for the employment of additional teaching staff. The school has extensive sporting facilities and much of the available funding coming from the community, raised through fund raising activities, is invested in keeping these facilities maintained.

School D is a state-funded, public school located in a middle-class neighbourhood that has undergone rapid urbanisation. The school is solely reliant on the state for teacher salaries and property maintenance. School D was the most underresourced school in our study. This was evident in teacher shortages, poorly maintained infrastructure, and lack of textbooks, computers, desks, paper, library books and teacher reference materials. 


\section{Findings and discussion}

The factors that constrain inclusive teaching can be grouped broadly into teacher factors, school factors, and broader systemic and societal factors. Clearly, though, these factors are interlinked, and we identify these separately for ease of discussion. The factors can then be further explained by seeing that different variants of an object-ofactivity reflected the historical motives of each school. Without exception, these historical motives of the object-of-activity were in contradiction with inclusive teaching.

\section{Constraining factors}

In this section we briefly discuss the constraining factors, and then outline four variants of an object-of-activity that we found to be in contradiction to inclusive teaching.

\section{Teacher factors}

All the teachers understood inclusive teaching to be where efforts were made to make education accessible for all learners. However, for many, solutions to make education accessible to all were associated with the ideas of special needs thinking in line with an individual deficit model of difference.

Most of the teachers approach learners who experience learning difficulties with a set of beliefs that constrain inclusive teaching. Teachers seem to subscribe to bellcurve thinking (Florian 2015) and view teaching learners who do not 'fit in' with the others as the skill-set of specialists. Expert assessment and diagnosis are considered important and a likely precursor to directing the learner to a special school. Vicky's [School C] solution to a learner who is experiencing difficulties is, 'Let's get this child tested, let's see which learning environment will suit him and move that child to a place 
of learning where he will enjoy it, because the child is frustrated here with me.' Teresa from School A also extolled the benefits of referring learners to other sources of support saying, 'We're fortunate to have all the learning support facilities where kids can go. We have these facilities which we can refer children to'. The principal of School C explained these 'facilities' further by saying,

We have support units for children who come into our system who need to be assisted. For ADHD children to be taken out of class for academic support, as well as more formal [therapy], even when children come in with Tourette syndrome and aspects like that where we have set up units with staff who are specially trained. At this school we have a permanent staff of about five on our staff who are dealing with these children on an individual basis every day.

Problems with learning are thus not framed as professional challenges for teachers, but as problems inherent in learners (Florian and Black-Hawkins 2011). The solution to learners who experience learning difficulties is to have them removed from regular classes and to send them to special support classes.

\section{School factors}

School factors beyond the attitudes of individual teachers include the school ethos, the role of leadership and the resources available in the school. Schools with a competitive ethos can be incompatible with inclusive teaching (Sapon-Shevin 2007). A competitive ethos was found to exist at School A. Here, parents expect the provision of a competitive advantage and view negatively anything that would impede this. As the principal explained: 'We need to take into consideration that there are twenty-four other children in the class [whose parents are] paying prime money to be here, to be extended [academically] and enriched, and anything that gets in the way of this process could be limiting.' He further intimated this tension/contradiction between the school's ethos 
and that of inclusive teaching when he said:

I think it is limited because of our ethos of actually extending the top pupils, more than helping children who have academic challenges. I think the demands of the parents, the expectations of the parents - we are very goal-orientated academically and are preparing children to get bursaries and to get into universities with top marks. And I think that that will have a direct negative bearing on our inclusivity.

Some principals are positive about the idea of inclusive teaching, like the principal of School D who acknowledged that there is minimal inclusive teaching at the school, which he is not 'happy about'. He 'would love [inclusive teaching] to happen, holistically at a large scale and then that would excite [him].' Other principals seem more ambivalent about being inclusive. Any inclusion of learners with disabilities at School A is conditional on their being able to cope with the stringent demands set by the school. The principal said,

Children with physical disabilities are included in our system as long as they are academically able to cope with the standards that we set, being a school that is earmarked to cater for average to above average pupils on the academic side.

Teachers recognise the importance of school leadership in providing the support and resources needed for inclusive teaching. Helen from School B commented, 'Because, when your job is becoming so much more difficult and you feel like you're not supported in doing that, it becomes almost impossible, especially when there's very little teacher support [from the principal].' Vicky from School C expressed frustration as she sees that management is fully invested in extra curricula activities 'This week we have athletics and a fun walk' which takes away from her teaching contact time. Reduced teaching time is also noted as a problem in School A. To achieve a competitive advantage, that school gives less time to the 'core subjects' in order to allow for 'extension options' [School A principal]. Georgina [School A] explained how 
this affects her when compulsory assessment activities need to be completed in a limited amount of teaching time, adversely impacting her ability to teach inclusively. This was reinforced by Teresa [School A], who said, 'You don't actually get to really attend to the kids, the slow learners - you, actually don't.'

Limited human and other resources constrain the uptake of inclusive education (Wildeman and Nomdo 2007). This is most evident at School D where limited school resources mean that teachers are left to improvise. Olive at School D complained that the limited human resources provided by the school make inclusive teaching difficult. 'You just devise means of helping them [learners]. The school doesn't help at all [with resources]'. She also commented about staff shortages: 'He was in Mama Paula's class so because we were short of teachers, we had to combine them.' This impacted on class size and limited the availability of human resources.

\section{Systemic factors}

Factors beyond the school gates also constrain inclusive teaching. The Department of Basic Education (DBE) is blamed for not providing the support needed for inclusive teaching. Olive [School D] said, 'It doesn't happen much [training for inclusive teaching], it is a problem, and then also there is a scarcity [materials]. The Department of Education talks about these things, in terms of saying we must do inclusive, but the playing field is not levelled.' While this complaint about the DBE is somewhat vague, participants are much more specific in their contention that the South African curriculum policy is an impediment to inclusive teaching. The constraints imposed by the curriculum relate to the amount of teaching content to be covered, type of assessment and fast pace of delivery. These are seen to mitigate against alternative assessment formats which some learners may require, against spending more time 
ensuring content mastery, and against providing support to learners. Sarah from School B complained about the pace she had to teach at to get through the content,

I find it very difficult because I think CAPS moves way too fast and so I struggle with, you know, how do I get that one kid to understand when he's going to take three weeks, when you just have to move and move and move?

The teachers reflected on the intensity of the curriculum and how planning materials do not consider different learning needs of individuals. This is evident when Theresa from School A said, 'It's an intense programme [the curriculum]. The minute you start working with a kid with a severe problem you actually have to have a proper worked out programme for that specific kid's needs [not provided by the CAPS].' The curriculum response to the assessment needs of individuals is also constrained, as explained by Helen from School B,

I think they make it difficult to be inclusive in terms of...how much content you have to pack in, and also how specific they [CAPS] are with things like assessments where it doesn't really make accommodation for the fact you might have to orally test a learner.

This finding confirms other South African studies that indicates that a rigid adherence to the directives of the curriculum and an inflexible approach to assessment constrains inclusive teaching (Geldenhuys and Wevers, 2013; Engelbrecht et al. 2015).

\section{Discussion}

Teacher factors, school factors and system factors that constrain inclusive teaching are, as we have shown, evident in the extant South African and international literature. But, as we noted in the introduction, we argue that further analysis is necessary to understand how these factors work to constrain inclusive teaching. In the discussion that follows we show how these factors lead us to identify four variants of object-of-activity that are 
incompatible with sustained, school-wide inclusive teaching. These variants are: an elitist/competitive ethos and a drive for academic success; an inflexible, lock-stepped and fast-paced curriculum; bell-curve thinking and the exclusion or marginalisation of some; and prioritising survival in the face of resource constraints. We discuss each of these variants with reference to the schools where there is evidence that they operate, noting that not all variants are applicable in all the schools. While these variants are described in the South African context, we contend that they would be applicable in other contexts too.

\section{Elitist/competitive ethos and a drive for academic success}

Where the historical motive (Kaptelinin 2005) in a school system is a drive for a narrowly defined academic success, all shared activity is directed towards achieving the outcome of high academic grades. The principal of School A reports that there is an expectation amongst parents that by sending their children to this school, the focus will be on academic achievement with all efforts directed towards assisting their children to attain grades that will allow access to desirable university programmes. Therefore, the ethos of pursuing academic success above other educational goals is motivated by parents.

The principal of School A reports that the parents hold the assumption that competitive advantage would be dulled by being inclusive. There is a contradiction between a motive to teach inclusively and one of competitive academic achievement. Historically, the school came into existence to provide education to a feepaying clientele demanding academic success and high matriculation grades. This historically motivated object informs the existing object-of-activity. Therefore, ideas 
around inclusive teaching have not had a disruptive effect on the existing object-ofactivity to the extent that it transforms.

\section{An inflexible and fast-paced curriculum}

At Schools B and C, the evolving motive informing the object-of-activity was strongly influenced by the provision of an education aligned with the directives of the CAPS curriculum, which dictated the lesson content and teaching pace. This resulted in a contradiction between inclusive teaching and the demands of the curriculum. At these schools, teachers are expected to achieve the school's object-of-activity of prescriptively adhering to the teaching requirements of the content of the curriculum. This contradiction exists between the subjects (teachers) and the rules components. This unresolved secondary contradiction constrained inclusive teaching, as teachers were under pressure to conform to the requirements of the curriculum.

\section{Bell-curve thinking and the exclusion or marginalisation of some learners}

At Schools A, B and C, learning difficulties are considered an indication of something wrong with a learner, rather than a teaching challenge. Testing, rather than the use of inclusive teaching strategies, is seen as the first response to learning difficulties that informs the actions that collectively manifest as the object of activity. This drives actions and activities towards an object-of-activity that advocates for separate educational settings to be the solution to learning difficulties, if not in a separate school, then in a separate unit with specialist teachers. We argue that when bell-curve thinking informs the object-of-activity, inclusive teaching is constrained. Instead of anticipating learner difference, schools see difference as problematic and so direct their activities towards finding alternative education provisions. Deficit labelling and segregation continue to dominate these schools, as it is their historical default position (Roth and 
Tobin 2002). The newer motive of inclusive teaching has not transformed the original object-of-activity (Kaptelinin 2005).

\section{Coping with the constraint of a lack of resources as a survival priority}

A lack of resources directs the motives that inform the object-of-activity at School D. This has a negative impact on inclusive teaching as the management decisions and teaching practices are directed at coping with the challenges of providing education without adequate human and physical resources. The teachers' efforts to manage these other constraints means that inclusive teaching is not considered a priority, but rather as an unattainable ideal. Even if the principal is in favour of inclusive teaching, he is constrained from promoting it because of a powerful existing, and untransformed object-of-activity in contradiction to the motives of inclusive teaching. Kaptelinin (2005) explains that the object-of-activity in a system is dynamically and continuously constructed based on contextual constraints. As Pantic (2015) points out, a teacher's agency can never be separated from the school structures or the availability of accessible resources. At School D the object-of-activity is constructed by the constraints of under-resourcing and social challenges. These frame the contradiction and inhibit the new motives of inclusive teaching from transforming the activity.

\section{Conclusion}

We conclude that the success of inclusive teaching depends on the ability of role players within schools to transform the object-of-activity. Schools that intend to embrace inclusive teaching must ensure that the motives that drive shared activities in the school are aligned with the aims and ideals of inclusive education. It becomes problematic when contradictions remain unresolved and where teachers or school leaders cannot effectively or systemically implement inclusive teaching practices in their schools 
because of pervasive, hidden motives. The findings presented in this article point to the need for the 'architecture' of schooling (Slee 2011,84) to be transformed if inclusive teaching is to be achieved and sustained. This transformation is no easy endeavour, with our findings attesting to the resilience of historical objects-of-activity that do not support inclusive teaching. But this resilience should not lead to a defeatist stance because schools can, and do change to become more inclusive. We thus make the following proposals based on Harris, Carrington, Aisncow et al's (2018) research into promoting equity in schools.

Three within-school strategies could be considered. The first is enhancing ethical school leadership that is committed to care, justice and critique in the face of policy demands. This means school leaders challenging 'all forms of inequality in order to create fairer and more responsive school practices' (Harris et al 2018, 124). It also means fostering a sense of community in schools and building 'local capacity for sustaining change' (p.140). Second, teachers can be encouraged in collaborative inquiry that gathers a variety of data to inform practice, in particular, to understand the impact of pedagogy on the learning of all their learners and to develop a 'language of practice' (p.157). This collaborative inquiry should be based in networks of learning across classrooms and even across schools. These ongoing learning networks should dislodge assumptions that teacher learning for inclusive teaching can be regarded as complete after initial teacher education or attendance at workshops. Finally, listening to the voices of learners can also be considered as a valuable way to understand what a school needs to do to become more inclusive. Learner voices, integrated with collaborative inquiry, can 'interrupt assumptions and provoke actions to create better outcomes for students' (p.81). These proposals are no quick-fix solutions, nor are they fully comprehensive, and we make them fully cognisant of the complexity of the South 
African historical, educational and socio-economic context in which they may be enacted. They do, however, offer a way forward in thinking about how inclusive education might become the 'sense-maker' in South African schools.

\section{Acknowledgements}

The authors gratefully acknowledge Professor Lani Florian of the University of Edinburgh for her critical and generative comments on an earlier draft of this paper.

The research reported in this article was funded by the South African National Research Foundation. 


\section{References}

Ainscow, M. and M. César. 2006. "Inclusive education ten years after Salamanca: Setting the agenda." European Journal of Psychology of Education 21 (3): 231238.

Beatty, I. D. and A. Feldman. 2012. "Viewing teacher transformation through the lens of cultural Historical Activity Theory." Education as Change 16 (2): 283-300.

Booth, T., M. Ainscow, K. Black-Hawkins, M. Vaughan and L. Shaw. 2002. Index for inclusion. Bristol: Centre for Studies on Inclusive Education.

Bryman, A. 2012. Social research methods $4^{\text {th }}$ edition. Oxford: Oxford University Press

Cohen, L., Manion, L., and Morrison, K. (2002). Research methods in education $6^{\text {th }}$ edition. New York: Routledge.

Creswell, J. W. and D. L. Miller. 2000. "Determining validity in qualitative inquiry." Theory into practice 39 (3): 124-130.

Department of Education. 2001. Education White Paper 6: Special needs education. Building an inclusive education and training system. Pretoria: Department of Education.

Donohue, D. and J. Bornman. 2014. "The challenges of realising inclusive education in South Africa." South African Journal of Education 34 (2): 1-14.

Ekins, A., H. Savolainen and P. Engelbrecht. 2016. “An analysis of English teachers' self-efficacy in relation to SEN and disability and its implications in a changing SEN policy context." European Journal of Special Needs Education 31 (2): 236249.

Ellis, V. 2011. "Reenergising professional creativity from a CHAT perspective: Seeing knowledge and history in practice.” Mind, Culture, and Activity 18 (2): 181-193.

Engelbrecht, P. 2013. "Teacher education for inclusion, international perspectives." European Journal of Special Needs Education 28 (2): 115-118.

Engelbrecht, P. 2004. "Changing roles for educational psychologists within inclusive education in South Africa." School Psychology International 25 (1): 20-29.

Engelbrecht, P., and M. van Deventer. 2013. "Impact on Teaching and Learning of Educational Policy on Special needs Education and Inclusion in South Africa." In Research on the Influences of Education Policy on Teaching and Learning, edited by C. V. Sunal and K. Mutua, 9 - 22. New York: Information Age Publishing. 
Engelbrecht, P., M. Oswald, E. Swart, A. Kitching and I. Eloff. 2005. "Parents' experiences of their rights in the implementation of inclusive education in South Africa." School Psychology International 26 (4): 459-477.

Engelbrecht, P., M. Nel, N. Nel and D. Tlale. 2015. "Enacting understanding of inclusion in complex contexts: classroom practices of South African teachers." South African Journal of Education 35 (3): 1-10.

Engelbrecht, P., M. Nel, S. Smit and M. Van Deventer. 2016. "The idealism of education policies and the realities in schools: the implementation of inclusive education in South Africa." International Journal of Inclusive Education 20 (5): 520-535.

Engestrom, Y. 1993. Developmental studies of work as a testbench of activity theory: The case of primary care medical practice. Understanding practice: Perspectives on activity and context, 64-103. Cambridge: University Press.

Engeström, Y. 1999. Innovative learning in work teams: Analyzing cycles of knowledge creation in practice. In Perspectives on activity theory, eds. Y. Engestrom, R. Miettinen and R.-L. Punamaki, 377-404. New York: Cambridge University Press.

Engestrom, Y. 2000. "Activity theory as a framework for analyzing and redesigning work." Ergonomics 43 (7): 960-974.

Engeström, Y. 2001. "Expansive learning at work: Toward an activity theoretical reconceptualization.” Journal of Education and Work 14 (1): 133-156.

European Agency for Development in Special Needs Education (EADSNE). 2012. Teacher education for inclusion: Profile of inclusive teachers. https://www.european-agency.org/sites/default/files/te4i-profile-of-inclusiveteachers_Profile-of-Inclusive-Teachers-EN.pdf

Florian, L. 2015. "Inclusive Pedagogy: A transformative approach to individual differences but can it help reduce educational inequalities?" Scottish Educational Review 47 (1): 5-14.

Florian, L. and K. Black-Hawkins. 2011. "Exploring inclusive pedagogy." British Educational Research Journal 37 (5): 813-828.

Foot, K. 2002. "Pursuing an evolving object: A case study in object formation and identification." Mind, Culture, and Activity 9 (2): 132-149. 
Geldenhuys, J. L. and N. E. J. Wevers. 2013. "Ecological aspects influencing the implementation of IE in mainstream primary schools in the Eastern Cape, South Africa." South African Journal of Education 33 (3): 1-18.

Gous, J. G., I. Eloff and M. C. Moen. 2014. "How inclusive education is understood by principals of independent schools." International Journal of Inclusive Education 18 (5): 535-552.

Harris, J., S. Carrington, M. Ainscow, B. Comber, L. Ehrich, V. Klenowski, et al. 2018. Promoting equity in schools: Collaboration, inquiry and ethical leadership. London: Routledge

Kaptelinin, V. 2005. “The object of activity: Making sense of the sense-maker.” Mind, culture, and activity 12 (1): 4-18.

Ladbrook, M. W. 2009. "Challenges experienced by teachers in the implementation of inclusive education in primary schools in South Africa”. PhD Diss., University of South Africa.

McMillan, H. and S. Schumacher. 2010. Research in Education: evidence-based enquiry. 7th ed. New Jersey: Pearson.

Merriam, S. B. 2002. Introduction to qualitative research. In Qualitative research in practice: Examples for discussion and analysis, eds. S. B. Merriam \& Associates. 5-18. San Francisco, CA: Jossey-Bass.

MacQueen, K. M., E. McLellan, K. Kay and B. Milstein. 1998. “Codebook development for team-based qualitative analysis." CAM Journal 10 (2): 31-36.

Nel, N. M. L. D., N. Tlale, P. Engelbrecht, and M. Nel. 2016. “Teachers' perceptions of education support structures in the implementation of inclusive education in South Africa." Koers 81 (3): 1-14.

Nilholm, C. and B. Alm. 2010. "An inclusive classroom? A case study of inclusiveness, teacher strategies, and children's experiences.” European Journal of Special Needs Education 25 (3): 239-252.

Pantić, N. 2015. "A model for study of teacher agency for social justice.” Teachers and Teaching 21 (6): 759-778.

Roth, W. M. and K. Tobin. 2002. 'Redesigning an 'urban' teacher education program: An activity theory perspective." Mind, Culture, and Activity 9 (2): 108-131.

Sapon-Shevin, M. 2007. "Widening the circle: The power of inclusive classrooms." Boston, MA: Beacon Press. 
Schafer, M., and D. Wilmot. 2012. "Teacher Education in Post-Apartheid South Africa: Navigating a way Through Competing State and Global Imperatives for Change." Prospects 42 (1): $41-54$.

Singh, S. and D. R. Wassenaar. 2016. "Contextualising the role of the gatekeeper in social science research." South African Journal of Bioethics and Law 9 (1): 4246.

Slee, R. 2014. "Discourses of Inclusion and Exclusion: drawing wider margins." Power and education 6 (1): 7-17.

Soudien, C. and Y. Sayed. 2004. "A New Racial State? Exclusion and Inclusion in Education Policy and Practice in South Africa." Perspectives in Education 22 (4): 101-116.

Stetsenko, A. 2005. "Activity as object-related: Resolving the dichotomy of individual and collective planes of activity." Mind, Culture, and Activity 12 (1): 70-88.

Teddlie, C. and F. Yu. 2007. "Mixed methods sampling: A typology with examples." Journal of mixed methods research 1 (1): 77-100.

UNESC0. 2018. Concept note for the Global Education Monitoring Report 2020 on inclusion. Paris: UNESCO. Accessed from https://unesdoc.unesco.org/ark:/48223/pf0000265329

UNESCO. 1994. The Salamanca Statement and Framework for action on special needs education: adopted by the World Conference on Special Needs Education; Access and Quality. Salamanca, Spain, 7-10 June 1994. Unesco.

United Nations (UN). 2016. General comment No. 4 (2016) on the right to inclusive education. Accessed from https://tbinternet.ohchr.org/_layouts/treatybodyexternal/Download.aspx?symbol no $=\mathrm{CRPD} / \mathrm{C} / \mathrm{GC} / 4 \&$ Lang $=\mathrm{en}$

United Nations (UN). 2015. Sustainable Development Goals, United Nations, New York. http://www.un.org/sustainabledevelopment/summit/ (accessed January 2018).

United Nations (UN). 2006. Convention on the Rights and Dignity of Persons with Disabilities. Accessed from http://www.un.org/disabilities/documents/convention/convoptprot-e.pdf 
Van Rooyen, B., L. Le Grange and R. Newmark. 2002. "Construction of functionalist discourses in South Africa's education White Paper 6: Special needs education." International Journal of Special Education 17 (2): 1-13.

Walton, E., N. M. Nel, H. Muller and O. Lebeloane. 2014. "You can train us until we are blue in our faces, we are still going to struggle': Teacher professional learning in a full-service school." Education as Change 18 (2): 319-333.

Walton, E. 2011. "Getting inclusion right in South Africa." Intervention in School and Clinic 46 (4): 240-245.

Wells, G. (1996). "Using the tool-kit of discourse in the activity of learning and teaching." Mind, Culture, and Activity 3 (2): 74-101.

Willig, C. 2008. Introducing qualitative research methods in psychology. Maidenhead, England: McGraw Hill.

Wildeman, R. A. and C. Nomdo. 2007. Implementation of inclusive education: How far are we? Report to IDASA on 7 March 2007. 